\title{
Hybrid Opacity in Berbice Dutch Creole
}

\author{
Michael Dow \\ Indiana University
}

\section{Introduction}

Opacity has recently received a fair amount of attention in the phonological literature, if mainly for the inability of classic Optimality Theory (OT) (Prince \& Smolensky 1993/2004) to derive opaque effects. In addition to modifications or expansions of OT, each with its own advantages and shortcomings, there is also a growing impetus to refine the taxonomy of opacity (especially Baković 2007, 2011). Though this work has to date revealed numerous areas where the theory is lacking, the mutual exclusivity of the two major kinds of opaque interactions, underapplication and overapplication, remains unquestioned. No single interaction has, until now, been reported to display both effects for a single input to output mapping.

I present one case from Berbice Dutch Creole (hereafter Berbice) where, depending on the analysis, nasal place assimilation simultaneously underapplies and overapplies, due to an interaction with consonant deletion. Specifically, this interaction depends on an underspecification analysis, where nasal consonants in homorganic NC sequences are derived from a placeless archiphoneme. When such a nasal is adjacent to a voiced stop, which is in turn adjacent to a heterorganic stop (e.g. /maNg-t $\varepsilon /$ 'run-ANT'), the nasal assimilates to the first consonant, which is ultimately deleted. As a result, the output form reflects the place of articulation of an absent segment but fails to re-assimilate to the now-adjacent heterorganic stop (e.g.

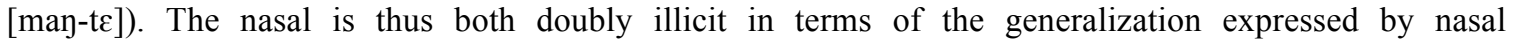
assimilation, and I dub this simultaneous underapplication and overapplication HYBRID OPACITY.

Different frameworks make different claims on the classification of this interaction, however. The above analysis is amenable to versions of rule-based serialism which avoid building predictable material in underlying representations but not to OT. The principle of Lexicon Optimization claims that homorganic NC outputs are best mapped from homorganic inputs (e.g. /mang-t $\varepsilon /$ ), as they introduce fewer faithfulness violations. This assertion would render the Berbice interaction a mere case of underapplication, as the nasal's place of articulation is not actively gained. However, a hypothetical archiphonemic or heterorganic mapping (e.g. /mamg-te/) is not problematic for opacity-tolerant models of OT, provided they can derive simple overapplication (or counterbleeding) effects. I show using an analysis in Optimality Theory with Candidate Chains (OT-CC) (McCarthy 2007) that the same grammar which derives the attested surface forms from homorganic inputs does as well from hypothetical underspecification and heterorganic inputs. All in all, both rule-based serialism and OT either insist on or allow for the existence of hybrid opacity.

While hybrid opacity is not unduly difficult to derive, it is messy for the theory and taxonomy of opacity, as opaque effects are often classified in mutually exclusive terms, i.e., underapplication and overapplication. Hybrid opacity resists a binary stratification. One could argue for its status as a type of overapplication with aspects of underapplication just as easily as for the opposite. Hybrid opacity incorporates selected elements of each type, but all elements of neither. I tentatively propose that, just as the line between transparency and opacity may be blurred in a single interaction (e.g. fed counterfeeding), so too may the line between underapplication and overapplication.

As no other hybrid opaque interaction has been documented as such, and as the one presented here is only conditionally so, I provide a generalized template in a deletion scenario to help identify further cases. I also discuss the possibility of experimentation with artificial languages to see if unquestionably hybrid opaque grammars can be acquired. Each of the two possible outcomes entails theoretical consequences: if we decide hybrid opacity must exist, a revised theory of opacity will need to take these phenomena into

\footnotetext{
* Acknowledgements: Special thanks to Daniel Dinnsen, Michael Becker, Kevin Rottet, Andries Coetzee, Stuart Davis, Jennifer Cole, San Duanmu, and the Midphon 18 audience for their input on early editions of paper. Many thanks also to Eric Baković, Matt Wolf, and Phonology 2013 reviewers and participants.
}

(C) 2014 Michael Dow

Supplemental Proceedings of Phonology 2013

Completed January 27, 2014 
account. If hybrid opacity must not exist, those frameworks which can derive it will need to adopt some sort of blocking mechanism in order to prevent overgeneration of grammars.

The organization of the paper is as follows: Section 2 presents the data from Berbice with both rulebased and optimality theoretic analyses. It also compares OT-CC with Turbidity (Goldrick 2001), which successfully derives the interaction but strikingly makes the claim that it is completely transparent regardless of input type. The discussion in $\S 3$ explores the implications of these analyses within both the received understanding of opacity and recent revisions to the theory. In $\S 4$, I lay out a general template for identifying hybrid opacity and provide the foundation for experimentation in artificial languages. Section 5 concludes the paper with a summary.

\section{Data and analysis}

Berbice is a now-extinct Dutch-based creole with an Eastern Ijo substrate, spoken in Guyana from the $17^{\text {th }}$ century until its death in 2005. All data come from Kouwenberg's (1994) grammar. Though the speakers demonstrate a fair amount of variation in some aspects (e.g. lexical choices, vowel allophony, etc.), the phenomena examined here show no variation with respect to etymological origin or speaker.

2.1 NC agreement, allophony, and assimilation In non-alternating environments, bilabial and alveolar nasal stops contrast word-initially, intervocalically, and in coda position. Before voiceless and voiced oral stops, only homorganic nasals are observed. ${ }^{1}$ Until we consider alternating forms, the only position where the velar nasal surfaces is before $[\mathrm{k}, \mathrm{g}]$. For reference, NT stands for nasal + voiceless stop, and ND for nasal + voiced stop sequence. NC refers either kind of sequence.

Nasal place contrast suspended before oral stops

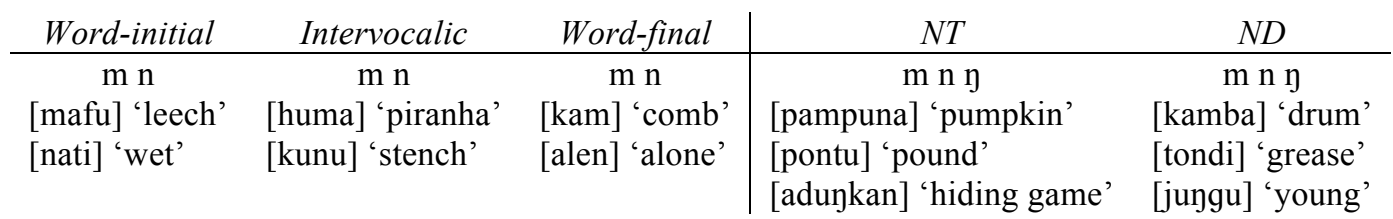

Alternations are observable in conjunction with a $\mathrm{V} \sim \varnothing$ alternation: via compounding in a limited number of cases, e.g. [sampoto] 'pepperpot' < [sani] 'pepper' + [poto] 'pot' and more frequently before the anterior marker $/$-t $\varepsilon /$. In these cases, [m] optionally alternates with $[\mathrm{n}]$. $^{2}$

Anterior forms optionally demonstrate place assimilation (“[nimi]-type” verbs)

\begin{tabular}{llll} 
& Bare forms & Anterior forms & Gloss \\
\hline a. & {$[$ nimi, nim $]$} & {$[$ nimi-t $\varepsilon$, nim-t $\varepsilon$, nin-t $\varepsilon]$} & 'know' \\
b. & {$[$ pama, pam $]$} & [pama-t $\varepsilon$, pam-t $\varepsilon$, pan-t $\varepsilon]$ & 'tell' \\
c. & {$[$ komu, kom $]$} & {$[$ komu-t $\varepsilon$, kom-t $\varepsilon$, kon-t $\varepsilon]$} & 'come'
\end{tabular}

The phonotactics observed in (1) and the assimilation in (2) work towards homorganic NC sequences.

These facts are often captured in rule-based frameworks capture by a single place assimilation rule. Since place agreement is invariable within monomorphs, the nasal's place of articulation may be derived from a placeless archiphoneme $/ \mathrm{N}$ / in order to avoid building predictable properties into underlying forms, e.g. $/ \mathrm{kaNba} / \rightarrow$ [kamba]. In compounds and [nimi]-type verbs, active assimilation is captured by ordering assimilation after vowel deletion. Both possible orderings are demonstrated below.

\footnotetext{
${ }^{1}$ There is a handful of fossilized exceptions, most [mt] or [md] (e.g. [femtika] 'honeycomb' and [nimdali] 'nothing'), and one instance of [mk] in [blumki] 'flower'.

${ }^{2}$ There are no labial- or velar-initial suffixes to test whether verbs containing alveolar nasals in their final syllables alternate with $[\mathrm{m}]$ before $[\mathrm{p}, \mathrm{b}]$ or with $[\mathrm{y}]$ before $[\mathrm{k}, \mathrm{g}]$.
} 
Possible interactions between vowel deletion and place assimilation

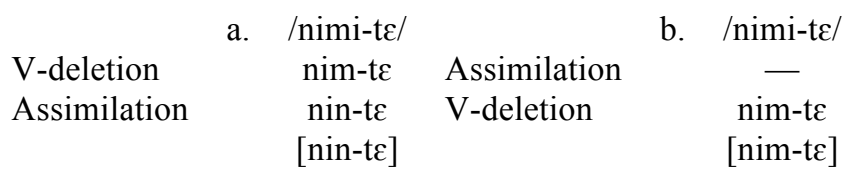

Application of vowel deletion first (3a) creates the environment for assimilation to apply, resulting in a surface representation true to the generalization that $\mathrm{NC}$ sequences are homorganic. This is typical of a classic FEEDING interaction. On the other hand, the inverse ordering of rules ( $3 \mathrm{~b}$ ) gives the also attested heterorganic sequence $[\mathrm{mt}]{ }^{3}$ Here, assimilation cannot re-apply once it has the proper environment if it is ordered before vowel deletion. As a result, the surface a form is untrue to the NC generalization. This is typical of a COUNTERFEEDING interaction.

Classic OT also accounts for the relevant phonotactics and alternations through a singular mechanism, though it crucially places no restrictions on input representations. In allophonic contexts, the input is not necessarily placeless, nor is it necessarily surface-true, even in the absence of alternations. For instance, surface [nd] may be derived in OT from $/ \mathrm{nd} /, / \mathrm{Nd} /, / \mathrm{md} /$ and so on. This is captured by a constraint banning heterorganic NC sequences (AGREE) outranking place faithfulness (ID[place]). ${ }^{4}$

NC agreement holds in monomorphs, regardless of input

a.

\begin{tabular}{|ll||c|c|}
\hline$/ \ldots \mathrm{Nd} . . . /$ & AGREE & ID[place] \\
\hline \hline a. & $\ldots \mathrm{Nd} \ldots$ & $* !$ & \\
\hline b. & $\ldots \mathrm{nd} . .$. & & $*$ \\
\hline
\end{tabular}

b.

\begin{tabular}{|c|c|c|}
\hline /...nd.../ & AGREE & ID[place] \\
\hline a. $\quad \ldots m d \ldots$ & $* !$ & $*$ \\
\hline b. $\quad \ldots$ nd... & & \\
\hline
\end{tabular}

However, without compelling evidence, one would not posit disagreeing inputs for homorganic surface sequences. Lexicon Optimization states that positing the underlying representation in (4a) introduces an unnecessary faithfulness violation, making (4b) optimal. However, as per Richness of the Base, the grammar of Berbice should be able to map any hypothetical input to a language-specific, phonotactically permissible output. Both input types will therefore be illustrated in the analysis, because the ultimate optimality theoretic grammar for Berbice will be able to derive the same output from all input types.

Classic OT captures the feeding interaction in [nin-t $\varepsilon$ ] but is unable to account for counterfeeding, as in

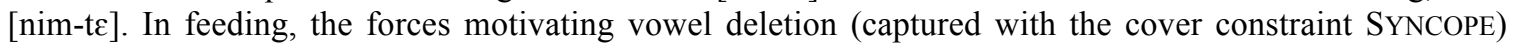
outrank faithfulness against vowel deletion (MAXV). The same rankings in (4) hold, allowing deletion to feed assimilation - here in parallel rather than serially.

Place assimilation fed by vowel deletion

\begin{tabular}{|ll||c:c|c:c|}
\hline \multicolumn{2}{|l|}{$/$ nimi-t $\varepsilon /$} & SYNCOPE & AGREE & ID[place] & MAXV \\
\hline \hline a. & $\operatorname{nimi}-\mathrm{t} \varepsilon$ & $* !$ & & & \\
\hline b. & $\operatorname{nim}-\mathrm{t} \varepsilon$ & & $* !$ & & $*$ \\
\hline c. & $\operatorname{nin}-\mathrm{t} \varepsilon$ & & & $*$ & $*$ \\
\hline
\end{tabular}

OT encounters a ranking paradox in the counterfeeding interaction. As the input nasal is necessarily bilabial (originally being in a contrastive position), retention of this information would require ID[place] to outrank AGREE. This option, however, is not available, given the behavior of NC sequences in monomorphs. Some extra mechanisms are required. An analysis of this interaction is not provided here but is similar to the counterfeeding presented at the end of $\$ 2.3 .2$.

Meanwhile, a large set of verbs ("[mangi]-type" verbs) forms a regular exception to NC place

\footnotetext{
${ }^{3}$ This display should not be taken to suggest that speakers employ a different rule ordering for each attested form. Otherwise, there would be no way of blocking unattested orderings for other input types. These pairwise orderings merely demonstrate how opacity works in rule-based serialism. (3a) should be taken as the "true" ordering, with assimilation as an optional rule.

${ }^{4} \mathrm{ID}$ [place] is generalized to include the spreading of a place feature to the placeless archiphoneme as in (4a). For the purposes of this paper, these effects are conflated with active changes in place.
} 
agreement, different than that previously seen. In both bare and anterior forms, these verb stems have two variants: nasal + voiced stop + vowel (NDV) and nasal-final (N).

[mangi]-type verbs: bare and suffixed forms

\begin{tabular}{llll} 
& Bare forms & Anterior forms & Gloss \\
\hline a. & {$[\mathrm{tambu}, \mathrm{tam}]$} & {$[\mathrm{tambu}-\mathrm{t} \varepsilon, \mathrm{tam}-\mathrm{t} \varepsilon], *[\mathrm{tan}-\mathrm{t} \varepsilon]$} & 'pound' \\
b. & {$[\mathrm{f} \varepsilon \mathrm{nd} \varepsilon, \mathrm{f} \varepsilon \mathrm{n}]$} & {$[\mathrm{f} \varepsilon \mathrm{nd} \varepsilon-\mathrm{t} \varepsilon, \mathrm{f} \varepsilon \mathrm{n}-\mathrm{t} \varepsilon]$} & 'find' \\
c. & {$[$ mangi, man $]$} & {$[$ mangi-t $\varepsilon, \operatorname{man}-\mathrm{t} \varepsilon], *[$ man-t $\varepsilon]$} & 'run'
\end{tabular}

The DV $\sim \varnothing$ alternation creates nasal-final variants with an apparent three-way contrast among [m, n, $\mathrm{n}]$ word-finally (bare forms) and in coda position (anterior forms). Whereas in non-alternating environments, [y] surfaces only by allophony, [mangi]-type verbs constitute a counterexample. In addition to this superficial contrast, suffixation in the anterior form routinely blocks place agreement, in contrast with the [nimi]-type verbs.

These stems are taken to be underlyingly ND-final for a number of reasons. First, the vowel in the NDV variants are largely predictable according to certain local factors: [ $\varepsilon$ ] after [-ATR] vowels, [u] after bilabial consonants, and [i] elsewhere. Second, NT(V) verbs such as [kanti] 'cannot' may reduce to NTfinal forms but not $\mathrm{N}$-final forms (e.g. [kant], *[kan]). As Berbice evidences a larger conspiracy against voiced obstruent codas in all positions, mappings of [tambu, tam] from /tamb/ are preferred over /tambu/. In the latter scenario, vowel deletion must feed consonant deletion on top of all other observed opacity, not to mention questions of predictability of and limitations on input forms (Dow 2013). Ultimately, whether /ND\#/ or /NDV\#/, the facts about assimilation hold: the voiced obstruent disappears, while the surface nasal unfailingly reflects that consonant's place of articulation.

The resultant type of opacity in the nasal-final stems of [mangi]-type verbs reflect a COUNTERBLEEDING interaction. In rule-based serialism, assimilation must apply before consonant deletion.

$$
\begin{aligned}
& \text { Assimilation precedes consonant deletion } \\
& \begin{array}{lclcc} 
& \text { a. } \quad / \mathrm{maNg} / & & \text { b. } & / \mathrm{maNg} / \\
\text { Assimilation } & \mathrm{mang} & \text { C-deletion } & \mathrm{maN} \\
\text { C-deletion } & \text { man } & \text { Assimilation } & - \\
& {[\mathrm{man}]} & & *[\mathrm{maN}]
\end{array}
\end{aligned}
$$

The attested derivation in (7a) is typical of a counterbleeding interaction in that the motivation for assimilation is later removed by consonant deletion. It is for this reason that a superficial contrast is obtained. The reverse order in (7b) is reflective of a BLEEDING interaction, as deletion removes the ability for assimilation to occur. Though it potentially results in a placeless consonant on the surface (a question not discussed here), it is transparent with respect to the input.

The counterbleeding interaction evidenced by $/ \mathrm{maNg} / \rightarrow[\mathrm{man}]$ is just as problematic for classic OT as counterfeeding. A constraint banning voiced obstruent codas (*VOC) outranks faithfulness against consonant deletion (MAXC). However, in parallel, any consonant motivating violation of ID[place] must also be present on the surface to be valid. Satisfaction of *VOC necessarily entails faithfulness to the input. The following tableau assumes the archiphonemic input for illustrative purposes. Note that the homorganic input would be unproblematic.

\begin{tabular}{|c|c|c|c|c|c|}
\hline$/ \mathrm{mal}$ & & $* \mathrm{VOC}$ & AGREE & ID[place] & MAXC \\
\hline a. & mang & $* !$ & & & \\
\hline b. & man & & & $*$ & $* !$ \\
\hline c. & $\mathrm{maN}$ & & & & * \\
\hline
\end{tabular}

$$
/ \mathrm{maNg} / \rightarrow[\mathrm{man}] \text { impossible in Classic OT }
$$

We now turn to the suffixed forms of these verbs and their unique properties. 
2.2 Hybrid opacity in Berbice The suffixed forms of [mangi]-type verbs must be derived with the same order of assimilation before consonant deletion, though the resulting interaction is noticeably different from that in $(7 a)$.

$$
\begin{aligned}
& \text { Assimilation and deletion in suffixed forms }
\end{aligned}
$$

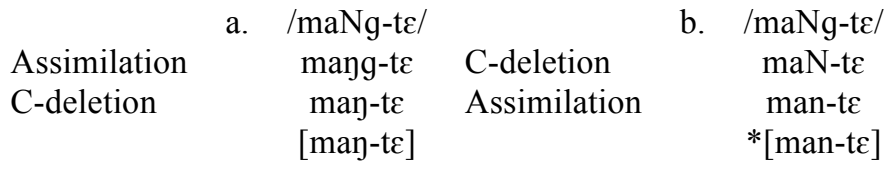

The counterbleeding interaction evidenced in (7a) still holds in (9a): superficial contrast is obtained, as [ $\mathrm{n}$ ] also appears permissible in word-internal codas, not just word-finally. However, deletion now also puts the (assimilated) nasal in contact with the stop-initial suffix. Crucially, assimilation cannot re-apply. [man-te] renders NC agreement untrue on the surface, thereby also meeting the criteria of a counterfeeding interaction. This sort of mapping is the essence of hybrid opacity, as it exhibits both types of interactions simultaneously. Interestingly enough, the inverse ordering (9b) is a "doubly transparent" combination of feeding and bleeding: deletion gives the nasal archiphoneme the chance to assimilate to the / $t /$ (feeding) but has also prevented it from assimilating to the $/ \mathrm{g} /$ (bleeding).

The derivation of [man-t $\mathrm{m}]$ from $/ \mathrm{maNg}-\mathrm{t} \varepsilon /$ fares even worse than the unsuffixed base in classic OT, as the attested candidate violates AGREE as well. Recall that hybrid opacity obtains only with heterorganic or

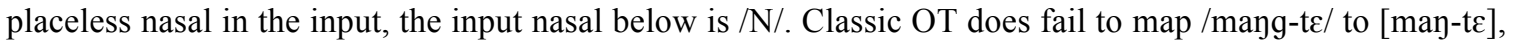
though for simpler reasons (discussed in $\$ 2.3 .2$ ).

\section{Classic OT fails to predict hybrid opacity}

\begin{tabular}{|ll||c|c|c|c|}
\hline \multicolumn{2}{|c|}{$/ \mathrm{maNg}-\mathrm{t} \varepsilon /$} & $*$ VOC & AGREE & ID [place] & MAXC \\
\hline \hline a. & mayg-t $\varepsilon$ & $* !$ & & & \\
\hline b. & may-t $\varepsilon$ & & $* !$ & $*$ & $*$ \\
\hline c. ${ }^{2}$ & man-t $\varepsilon$ & & & $*$ & $*$ \\
\hline
\end{tabular}

Classic OT can derive neither the bare bases (counterbleeding), nor the suffixed forms of [mangi]-type verbs (hybrid opacity). It is with these complications in mind that we turn to OT-CC.

2.3 Optimality Theory with Candidate Chains Optimality Theory with Candidate Chains is one of the few extensions of OT which can derive both underapplication and overapplication effects, though at the expense of reintroducing serialism to OT. OT-CC operates on two fundamental principles: First, output candidates are no longer infinite but rather a limited set of local unfaithful mappings (LUM) which diverge from a fully faithful candidate. LUM sequences (LUMseq) are restricted in that they must always: (1) depart from this fully faithful representation, (2) make only gradual changes with each successive step, equal to one faithfulness violation, and (3) improve harmonically.

Second, a new family of constraints, PRECEDENCE, evaluates output candidates. A constraint such as $\operatorname{PREC}(A, B)$ specifies an optimal sequence of faithfulness violations of $\langle A, B>$, whereby a violation of $B$ must be preceded by and not followed by a violation of $\mathrm{A}$. For instance, a LUMseq of $<\mathrm{B}>$ or $<\mathrm{A}, \mathrm{B}, \mathrm{A}>$ incurs one violation, whereas $<\mathrm{A}, \mathrm{B}>$ incurs no violations and $<\mathrm{B}, \mathrm{A}>$ incurs two.

2.3.1 OT-CC analysis I: /maNg-te/ Entertaining first input placeless nasals in NC sequences (which also mirrors hypothetical heterorganic inputs), possible candidate chains will build upon violations of ID[place] and MAXC. The relevant PRECEDENCE constraint must prevent deletion before place assimilation. Therefore, the ideal violation sequence is ID[place] followed by MAXC, or PREC(ID[place], MAXC). Installing this constraint below the forces motivating consonant deletion but above those producing assimilation ensures the proper results. Note that up till now, *VOC and AGREE have both been undominated over MAXC and ID[place]. This ranking works for the derivation of $/ \mathrm{maNg} /$ but will not for the suffixed form. The tableau below reflects that eventual argument. 


$$
\begin{aligned}
& \text { Derivation of } / \mathrm{maNg} / \\
& \text { Ranking: *VOC }>>\text { MAXC }>>\text { PREC(ID[place], MAXC) }>>\text { AGREE }>>\text { ID[place] }
\end{aligned}
$$

\begin{tabular}{|c|c|c|c|c|c|c|}
\hline \multicolumn{2}{|c|}{$/ \mathrm{maNg} /$} & $* \mathrm{VOC}$ & MAXC & PREC & AGREE & $\mathrm{ID}[\mathrm{pl}]$ \\
\hline a. & $\begin{array}{l}<\mathrm{maNg}> \\
\varnothing\end{array}$ & $* !$ & & & $*$ & \\
\hline b. & $\begin{array}{l}<\mathrm{maNg}, \mathrm{maN}> \\
\mathrm{MAxC}\end{array}$ & & $*$ & $* !$ & & \\
\hline c. & $\begin{array}{l}<\text { maNg, mayg }> \\
\text { ID[place] }\end{array}$ & $* !$ & & & & $*$ \\
\hline d. & $\begin{array}{l}<\text { maNg, mayg, may }> \\
\text { ID[place], MAXC }\end{array}$ & & $*$ & & & $*$ \\
\hline
\end{tabular}

The PREC constraint ensures that the transparent bleeding candidate (11b) does not win.

The derivation of the suffixed form $/ \mathrm{maNg}$-t $\varepsilon /$ is similar, though with a few extra sequences, some of which are phonetically identical but whose derivational histories differ.

\begin{tabular}{|c|c|c|c|c|c|c|}
\hline \multicolumn{2}{|c|}{$/ \mathrm{maNg}-\mathrm{t} \varepsilon /$} & *VOC & MAXC & PREC & AGREE & $\mathrm{ID}[\mathrm{pl}]$ \\
\hline a. & $\begin{array}{l}<\mathrm{maNg}-\mathrm{t} \varepsilon> \\
\varnothing\end{array}$ & $* !$ & & & $*$ & \\
\hline b. & $\begin{array}{l}<\operatorname{maNg}-\mathrm{t} \varepsilon, \mathrm{maN}-\mathrm{t} \varepsilon> \\
\mathrm{MAXC}\end{array}$ & & $*$ & *! & $*$ & \\
\hline c. & $\begin{array}{l}<\mathrm{maNg}-\mathrm{t} \varepsilon, \text { maN-t } \varepsilon, \text { man-t } \varepsilon> \\
\text { MAXC, ID[place] }\end{array}$ & & $*$ & $* ! *$ & & $*$ \\
\hline d. & $\begin{array}{l}<\operatorname{maNg}-\mathrm{t} \varepsilon, \operatorname{mang}-\mathrm{t} \varepsilon> \\
\text { ID[place] }\end{array}$ & $* !$ & & & & $*$ \\
\hline e. & $\begin{array}{l}<\operatorname{maNg}-\mathrm{t} \varepsilon, \text { mang-t } \varepsilon, \operatorname{man}-\mathrm{t} \varepsilon> \\
\text { ID[place], MAXC }\end{array}$ & & $*$ & & $*$ & $*$ \\
\hline & $\begin{array}{l}<\text { maNg-t } \varepsilon, \text { mang-t } \varepsilon, \text { man-t } \varepsilon, \text { man-t } \varepsilon> \\
\text { ID[place], MAXC, ID[place] }\end{array}$ & & $*$ & $* !$ & & $* *$ \\
\hline
\end{tabular}

Derivation of $/ \mathrm{maNg}-\mathrm{t} \varepsilon /$

As clear from the violation profile of (12e), AGREE cannot be ranked anywhere over PREC if the proper results are to obtain. Otherwise, assimilation would reoccur (12f). Crucially, the winning candidate violates markedness pertaining to assimilation (AGREE) as a result of assimilation (violation of ID[place]). It is illicit on all accounts except the never-violated *VOC and PREC itself. However, this sort of input is not optimal for existing words in Berbice. Yet there will be no difference in the ranking hierarchy using these inputs - only a difference in the resultant type of opacity.

2.3.2 OT-CC analysis II: /mayg-te/ Upon adopting homorganic input ND sequences, both the valid candidate chains and their violation profiles change. As the coda nasal in bases would no longer actively gain its place via assimilation, it displays mere underapplication. In the bare forms, only two chains are valid: <mang $>$ and <mang, may $>$. The former loses due to *VOC, despite the latter's violation of PREC. A similar story holds for suffixed candidates. Here, only three chains are valid, as there is no "Assimilation first" path. The winner incurs a violation of AGREE in satisfaction of PREC. 
Derivation of /mang-te/

\begin{tabular}{|c|c|c|c|c|c|c|}
\hline \multicolumn{2}{|c|}{$/ \mathrm{mang}-\mathrm{t} \varepsilon /$} & *VOC & MAXC & PREC & AGREE & $\mathrm{ID}[\mathrm{pl}]$ \\
\hline a. & $\begin{array}{l}<\text { mang-t } \varepsilon> \\
\varnothing\end{array}$ & *! & & & & \\
\hline b. & $\begin{array}{l}<\operatorname{mang}-\mathrm{t} \varepsilon, \operatorname{man}-\mathrm{t} \varepsilon> \\
\text { MAXC }\end{array}$ & & $*$ & $*$ & * & \\
\hline c. & $\begin{array}{l}<\text { mang-t } \varepsilon, \text { man-t } \varepsilon, \text { man-t } \varepsilon> \\
\text { MAXC, ID[place] }\end{array}$ & & $*$ & $* * !$ & & $*$ \\
\hline
\end{tabular}

The presence of the coda [ $\mathrm{y}]$ in the winner (13b) is underapplication of AGREE. However, crucially, it is not actively derived, as with the archiphonemic input; the overapplication aspect disappears entirely here.

2.4 Other frameworks As stated earlier, true cases of hybrid opacity may be derived only by those frameworks which can derive simple overapplication effects. For this reason, Local Constraint Conjunction (Smolensky 1995) and Comparative Markedness (McCarthy 2002) fail to model hybrid opacity. There is no way of motivating violation of input faithfulness if the triggering consonant is not present on the surface. Curiously, these two do allow for a ranking argument which produces counterfeeding via bleeding (e.g. $/ \mathrm{mgt} / \rightarrow[\mathrm{mt}])$, which neither rule ordering nor OT-CC can model, without adopting optional rules or Wolf's (2011) split PREC approach.

As a non-serial model which can derive hybrid opacity, Turbidity (Goldrick 2001), offers an intriguing solution which makes radically different claims concerning the nature of the interaction. Briefly put, this approach uses enriched output representations where covert structure may be present though unpronounced. Markedness constraints are reconceptualized as antagonistic PROJECT and PRONOUNCE constraints, and faithfulness constraints are retained. The hybrid opacity (i.e., archiphonemic or heterorganic) account of Berbice may be captured by positing a mismatch between pronounced voiced stop codas and projected heterorganic ND sequences. The relevant constraints and tableaux, following Baković's (2007) notation, are given below. An underlined segment $(14 \mathrm{c}, \mathrm{d}, \mathrm{i}, \mathrm{j})$ represents projected but unpronounced structure.

(14) Turbidity account of hybrid opacity

PROJECTAGREE: Nasal + stop sequences must agree, pronounced or not. NoPRONOUNCEVOC: Voiced obstruent codas must not be pronounced. PRONOUNCE(C): Input consonants must be pronounced (no deletion).

\begin{tabular}{|c|c|c|c|c|c|}
\hline \multicolumn{2}{|c|}{$/ \mathrm{maNg} /$} & PROJAGREE & NoPRONVOC & $\operatorname{PRON}(\mathrm{C})$ & ID[place] \\
\hline a. & $\ldots \mathrm{Ng}$ & $* !$ & $*$ & & \\
\hline b. & ...ng & & $* !$ & & $*$ \\
\hline c. & $\ldots \mathrm{Ng}$ & $* !$ & & & \\
\hline d. & $\ldots . n g$ & & & & $*$ \\
\hline e. & $\ldots \mathrm{N}$ & & & $* !$ & \\
\hline f. & $\ldots y$ & & & $* !$ & $*$ \\
\hline \multicolumn{6}{|c|}{ /maNg-te/ } \\
\hline g. & ...Ngt... & $* !$ & * & & \\
\hline h. & ...ngt... & & $* !$ & & * \\
\hline i. & ...Ngt... & $* !$ & & & \\
\hline j. & ...pgt... & & & & $*$ \\
\hline $\mathrm{k}$. & $\ldots \mathrm{Nt} .$. & $* !$ & & $*$ & \\
\hline 1. & ...nt... & & & $* !$ & $*$ \\
\hline
\end{tabular}


In both winning candidates, the velar stop is present (i.e., projected) at a level of structure without being pronounced. This motivates assimilation with the velar without the need to violate the phonotactics of Berbice. In suffixed forms, the intervening projected velar stop prevents assimilation with the coronal stop, no longer adjacent to the nasal consonant. This layer of projected structure in essence preserves information ${ }^{5}$ which the OT-CC analysis claims is missing. Re-assimilation (the underapplication aspect) is blocked in OT-CC because of architectural reasons, whereas Turbidity removes all motivation for assimilation with the coronal. As a result, there is no opacity involved in either scenario in (14). For now, this paper makes no claims concerning which analysis is optimal, though see McCarthy (2007) for the limitations of enriched output approaches such as this and Sympathy, mostly involving overgeneration.

\section{Discussion}

Comparing the two OT-CC analyses, we see that the hybrid opacity scenario (amenable to rule-based serialism) is produced by the same ranking which derives underapplication from homorganic ND sequences. Though Berbice is only conditionally an example of hybrid opacity, it calls attention to the theoretical possibility of such an interaction. The questions that follow from its existence concern its classification, minimal criteria and further identification.

3.1 Taxonomy of opacity As hybrid opacity displays both underapplication and overapplication, it resists classification in the current taxonomy of opacity. One would rightfully ask whether it should be considered a particular instantiation of one type of opacity (which happens to include aspects of the other) or its own independent type. The latter seems the more promising description, given the particular characteristics of hybrid opacity.

Recalling the standard definition of opacity, some difficulties arise in establishing correspondences between segments in mappings and their corresponding elements in the definition.

Standard definition of opacity (Kiparsky 1973)

A phonological rule $\mathrm{P}$ of the form $\mathrm{A} \rightarrow \mathrm{B} / \mathrm{C} \_\mathrm{D}$ is opaque if there are surface structures with either of the following characteristics:

a. instances of $\mathrm{A}$ in the environment $\mathrm{C} \_\mathrm{D}$

b. instances of $\mathrm{B}$ derived by $\mathrm{P}$ that occur in environments other than $\mathrm{C}_{-} \mathrm{D}$

The opaque segment in hybrid opacity would need to be ' $A$ ' and ' $B$ ' simultaneously. In a $/ \mathrm{maNg}$-t $\varepsilon / \rightarrow$ [man-tc], the velar nasal is clearly the structural change (B) brought about by the assimilation rule, yet the underapplication aspect invokes its role in the focus (A) of the same rule. In contrast with a standard underapplication scenario, where the rule never applies, $\mathrm{P}$ has applied once; underapplication depends on the rule's failure to apply a second time. Hybrid opacity may therefore be seen as the failure of cyclicity within an overapplication scenario.

From the point of view of rule interactions, hybrid opacity is hybrid specifically because of the provenance of each effect.

Typology of rule interactions (as adapted by Baković 2011)

Given two rules A, B such that A precedes B,

a. A FEEDS B iff A creates additional inputs to B.

b. A BLEEDS B iff A eliminates potential inputs to B.

c. B COUNTERFEEDS A iff B creates additional inputs to A.

d. B COUNTERBLEEDS A iff B eliminates potential inputs to A.

\footnotetext{
${ }^{5}$ In this aspect, Turbidity is like Lubowicz's Preservation of Contrast theory (2003, 2012), which understands opacity as a means of preserving contrasts by transforming them. An analysis in this theory is not provided here, though this is an interesting avenue for future work.
} 
Given the order of assimilation (A) before consonant deletion (B), deletion creates additional inputs to assimilation as well as eliminating potential inputs to it - but crucially on different sides of deletion. $|\mathrm{yg}|$ or $|\mathrm{Ng}|$ as potential (but eliminated) inputs to assimilation, however vacuous, are independent of $|\mathrm{yt}|$ as a potential (but retained) input to the same rule. Nothing about (16c) states that the rule must not have already applied, which was tangled up in the phrasing of (15). The serial language of these definitions are amenable to hybrid opacity, in keeping with McCarthy's (2007) conclusions about serialism's fundamental tie to opacity.

The result is the sum of its parts, each of which may be understood separately rather than being mutually exclusive. Stated in other terms, in plain counterfeeding interactions, the underlying representation meets the structural description of only the second rule $(B)$, whose application produces an output meeting the structural description of the first rule (A). On the other hand, in plain counterbleeding interactions, the underlying representation meets the structural description of both rules: rule B's application is independent of that of rule A. However, after rule B's application, the output is no longer relevant to the conditions specified by rule A. In hybrid opacity, though the input meets the structural description of both rules (meaning that rule B's application is again independent), the result of rule B does meet the description of rule A.

Rule application and structural description satisfaction

\begin{tabular}{rlll} 
& Counterfeeding & Counterbleeding & Hybrid opacity \\
\hline UR meets the structural description of... & B & A, B & A, B \\
Does A apply? & no & yes & yes \\
Does B apply? & yes & yes & yes \\
Does the output of B meet & yes & no & yes \\
the structural description of A? & & &
\end{tabular}

All in all, hybrid opacity has some, but not all, elements of each. Rather than classifying it as a type of overapplication with underapplication elements or vice-versa, hybrid opacity will likely need to be thought of as its own type of opacity. The question, however, is left open until more instances of the phenomenon can be identified.

3.2 Criteria and templates As the Berbice data provided inconclusive evidence for hybrid opacity, given issues surrounding the input nasal, it is worth examining which criteria must be present to obtain such an interaction. To this end, a deletion template is given below. ${ }^{6}$ This template is then fleshed out into a possible experimental paradigm.

3.2.1 Deletion template In the deletion scenario, certain conditions must be met in the underlying forms as well as in the order of changes.

Deletion template for hybrid opacity

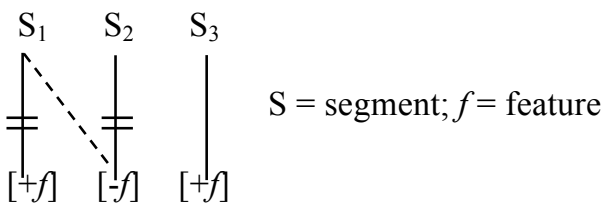

$\mathrm{S}_{1}$ and $\mathrm{S}_{2}$ either have disagreeing coefficients of $f$ or mutually exclusive monovalent values for the same property (e.g. place features). $\mathrm{S}_{1}$ may also be underspecified for $f$, as long as its default value disagrees with that of $S_{2} . S_{1}$ may participate in a process adjacent to either $S_{2}$ or $S_{3}$ (i.e., $S_{1} S_{2}$ and $S_{1} S_{3}$ may both participate), such that $S_{1}$ may inherit the feature of the other $S$; call this process $P$. The feature value of $S_{2}$

\footnotetext{
${ }^{6}$ An epenthesis template is also possible but omitted for space. Other avenues to explore include vowel harmony and suprasegmental interactions.
} 
spreads to $\mathrm{S}_{1}$ via $\mathrm{P} . \mathrm{S}_{2}$ is marked in its position for reasons independent of $\mathrm{P}$ and thus deletes. $\mathrm{P}$ does not reoccur, i.e., $[+f]$ does not spread from $\mathrm{S}_{3}$ to $\mathrm{S}_{1}$.

To give a hypothetical example, consider a language with (a) regressive $[\alpha$ voice] assimilation in consonant clusters, such that /al-ta/ becomes [al-ta] and /at-ba/ $\rightarrow$ [ad-ba], and (b) reduction of complex codas, such that $\mathrm{C}_{1} \mathrm{C}_{2}$ clusters to $\mathrm{C}_{1}$, whereby /ald/ $\rightarrow$ [al] and /ald-ba/ $\rightarrow$ [al-ba]. The appropriate input would involve /alt-ba/, by virtue of its alternating [voice] values and the targeting of the second, [-f] segment by deletion. If voicelessness spreads to the liquid before the deletion of the stop, we obtain the hybrid opaque output [al-ba]. Not only should the liquid not have devoiced according to assimilation, but also it is refusing to assimilate with the ultimately adjacent segment. Again, assuring $/ 1 /$ over $/ 1 /$ is crucialideally, not only would the voiceless liquid be non-contrastive, but also evidence from alternations would ensure the voiced liquid in this word's input.

3.2.2 Artificial language testing Experimental evidence from artificial language testing may also provide arguments for or against hybrid opacity, allowing for control of alternations and other confounding factors. Learners would be presented with a language with roots of different shapes and several meaningbearing suffixes. Learners would also be presented with processes whereby coda clusters are resolved word-internally and word-finally by deletion of the second member, and heterorganic NC clusters are resolved by nasal place assimilation. Just as in Berbice, assimilation would precede consonant deletion.

Hypothetical language paradigms: deletion scenario

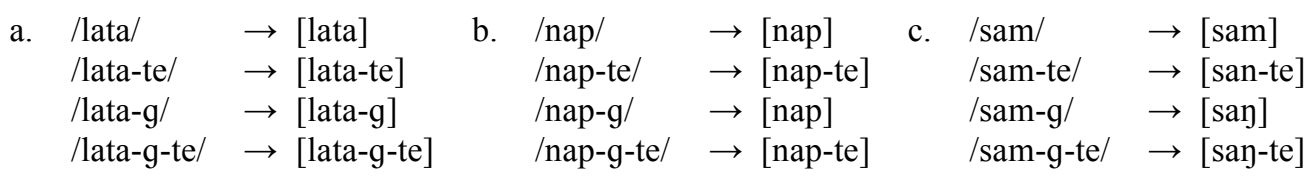

Type (19a) teaches morphology, while (19b) shows that deletion may create ambiguity. Type (19c), however, allows the relevant morphology to be preserved via transformation. Evidence of the nasal's bilabial place of articulation in $/ \mathrm{sam} / \rightarrow$ [sam] resolves the issues surrounding the Berbice data. Whether learners can generalize to [say-te] while allowing the ambiguity in (19b) is the crucial question. If yes, this may argue for the possibility of hybrid opacity, with or without its documentation in natural languages. Conversely, should learners be unable to acquire hybrid opacity, it may be necessary to revisit those frameworks which allow for it, in order to avoid overgeneration of grammars. That is, if hybrid opacity is unattested and/or proves impossible to learn, some sort of mechanism may need to be instated to block its potential derivation.

\section{Summary and conclusions}

Depending on the nature of the input nasal segment in Berbice, which fell out of the architecture of the framework used, the interaction between nasal assimilation and consonant deletion could yield output forms where assimilation both underapplied and overapplied. Neither serial rule ordering nor OT-CC had any difficulty deriving such an interaction, regardless of whether these forms were ideally the underlying forms for the words in question. The existence of hybrid opacity is therefore a possibility worth exploring outside of the Berbice interaction.

More than anything, hybrid opacity poses a problem for the taxonomy of opacity, as its classification resists binary distinctions. The interaction features some but not all hallmarks of each "type" of opacity. Altogether, the facts tentatively suggest that hybrid opacity is its own independent type, which was quite intuitively modeled by serialism. That is, rather than "types" of opacity, one might return to a type of theory of interactions, which are not necessarily unary.

However, conclusively determining the existence of hybrid opacity remains to be done. Should hybrid opacity exist, revisions to the taxonomy and/or definition of opacity will need to be considered. Should we decide that hybrid opacity must not exist, the overgeneration problem will need to be resolved on a caseby-case basis, since the mechanisms blocking hybrid opacity would have to stem from different sources (e.g. restrictions on inputs, rule application, sequences of faithfulness violations, etc.). 


\section{References}

Baković, Eric. (2007). A revised typology of opaque generalisations. Phonology, 24(2), 17-259.

Baković, Eric. (2011). Opacity and ordering. In John Goldsmith, Alan Yu \& Jason Riggle (Eds.), The Handbook of Phonological Theory (2 ed., pp. 40-67). Oxford: Wiley-Blackwell.

Dow, Michael. (2013). Multiple repairs for voiced obstruent codas in Berbice Dutch Creole. Paper presented at the Manchester Phonology Meeting, Manchester, England.

Goldrick, Matthew. (2001). Turbid output representations and the unity of opacity. In Masako Hirotani, Andrew Coetzee, Nancy Hall \& Ji-Yung Kim (Eds.), Proceedings of the Northeast Linguistics Society (NELS) 30 (Vol. 1, pp. 231-245). Amherst, MA: GLSA.

Kavitskaya, Darya, \& Staroverov, Peter. (2010). When an interaction is both opaque and transparent: the paradox of fed counterfeeding. Phonology, 27(2), 255-288.

Kiparsky, Paul. (1973). Abstractness, opacity, and global rules. In Osamu Fujimura (Ed.), Three Dimensions of Linguistic Theory (pp. 57-86). Tokyo: TEC.

Kouwenberg, Silvia. (1994). A Grammar of Berbice Dutch Creole. Berlin: Mouton de Gruyter.

Łubowicz, Anna. (2003). Contrast Preservation in Phonological Mappings. (Ph.D.), University of Massachusetts, Amherst.

Łubowicz, Anna. (2012). The Phonology of Contrast. London: Equinox.

McCarthy, John. (2002). Comparative Markedness (Long Version). In Angela Carpenter, Andrew Coetzee \& Paul de Lacy (Eds.), Papers in Optimality Theory II [University of Massachusetts Occasional Papers in Linguistics 26] (pp. 171-246). Amherst, MA: GLSA.

McCarthy, John. (2007). Hidden Generalizations: Phonological Opacity in Optimality Theory. London: Equinox.

Prince, Alan, \& Smolensky, Paul. (1993/2004). Optimality Theory: Constraint interaction in generative grammar. Oxford: Wiley-Blackwell.

Smolensky, Paul. (1995). On the structure of the constraint component CON of UG. Paper presented at the University of California, Los Angeles.

Wolf, Matthew. (2011). Limits on global rules in Optimality Theory with Candidate Chains. Phonology, 28(1), 87-128. 